\title{
Ectomycorrhizal fungal communities in ice-age relict forests of Pinus pumila on nine mountains correspond to summer temperature
}

\author{
Takahiko Koizumi iD $^{1,2} \cdot$ Kazuhide Nara $^{1}$
}

Received: 27 March 2019 / Revised: 11 September 2019 / Accepted: 16 September 2019 / Published online: 14 October 2019

(c) The Author(s), under exclusive licence to International Society for Microbial Ecology 2019

\begin{abstract}
Ectomycorrhizal (ECM) fungi are critical symbionts of major forest trees, and their communities are affected by various environmental factors including temperature. However, previous knowledge concerning temperature effects does not exclude the effects of host species and coexisting plants, which usually change with temperature, and should be rigorously tested under the same vegetation type. Herein we examined ECM fungal communities in ice-age relict forests dominated by a single host species (Pinus pumila) distributed on nine mountains across $>1000 \mathrm{~km}$ in Japan. Direct sequencing of rDNA ITS regions identified 154 ECM fungal species from 4134 ECM root-tip samples. Gradient analyses revealed a large contribution of temperature, especially summer temperature, to ECM fungal communities. Additionally, we explored global sequence records of each fungal species to infer its potential temperature niche, and used it to estimate the temperature of the observed communities. The estimated temperature was significantly correlated with the actual temperature of the research sites, especially in summer seasons, indicating inherent temperature niches of the fungal components could determine their distribution among the sites. These results indicate that temperature is still a significant determinant in structuring ECM fungal communities after excluding the effects of host species and coexisting plants. The results also imply that the rising temperature under global warming may have been affecting soil microbes unnoticeably, while such microbial community change may have been contributing to the resilience of the same vegetation.
\end{abstract}

\section{Introduction}

Many forest trees establish symbiotic associations with ectomycorrhizal (ECM) fungi to acquire soil nutrients in exchange for photosynthates [1]. Associating with diverse ECM fungi enables host trees to access various forms of soil nutrients and to adapt better to environmental changes $[2,3]$. Additionally, ECM associations improve tolerance to drought $[4,5]$ and soil-borne plant pathogens [6-8].

Supplementary information The online version of this article (https:// doi.org/10.1038/s41396-019-0524-7) contains supplementary material, which is available to authorized users.

Takahiko Koizumi

takahiko.koizumi@gmail.com

1 Department of Natural Environmental Studies, Graduate School of Frontier Sciences, The University of Tokyo, 5-1-5 Kashiwanoha, Kashiwa, Chiba 277-8563, Japan

2 Present address: Department of Biosciences, College of Humanities and Sciences, Nihon University, 3-25-40 Sakurajosui, Setagaya-ku, Tokyo 156-8550, Japan
Because of these critical functions of ECM fungi, forest trees largely rely on ECM associations under natural conditions [1,9]. Therefore, ECM fungi are regarded as key components of temperate and boreal forest ecosystems.

Various factors are proposed to influence ECM fungal communities, including geographical location [10-12], climate, such as temperature and precipitation [13-16], edaphic conditions [17, 18], and host identity [19-22]. Relatively strong effects of climate on ECM fungal communities have been demonstrated using an elevational gradient with the advantage of large climatic variation within a narrow spatial range [13, 23]. However, previous studies did not completely exclude the confounding effect of tree composition, which usually covaries with climate or altitude. Scattolin et al. [24] focused on a single host species, i.e., Quercus ilex, in Sardinia and found a significant effect of altitude on ECM fungal communities. The observed effect of the altitude may be related to climate variables in their study, but it remains to be confirmed in comparison with other potential factors (e.g., precipitation, soil types, and coexisting plants). 
Among climate factors, temperature has been shown to explain the largest variance in ECM fungal communities by gradient analysis [14, 16, 25]. In addition, Miyamoto et al. [26] examined temperature niches of ECM fungi based on regional species occurrence data and found that temperature niche ranges varied significantly among fungal taxa. These previous studies used only mean annual temperature and none of them considered seasonal temperature variation. Furthermore, the observed temperature effects in previous studies may partly be attributed to different tree composition, as described above. To better understand the effect of temperature on ECM fungal communities, it would be ideal to examine the effect of the seasonal temperature variations on the communities in forests composed of a single host species across a wide temperature range.

Pinus pumila (Pinaceae) forms monodominant dwarf shrub forests above the tree line in alpine regions in Japan [27-29]. This pine species migrated from Siberia to Japan during the ice-ages. After the last ice-age, the main distribution range of $P$. pumila has moved back to Siberia but some populations are left in Japan and confined to higher mountains over a wide geographic area. Moreover, because the altitude of these mountains varies considerably, the temperature variation among $P$. pumila forests is large. Thus, the ice-age relict $P$. pumila forest system may be ideal to examine the effect of temperature on ECM fungal communities under the same vegetation type, where the effect of host species and coexisting plants could be minimized.

Alpine ecosystems, especially ice-age relict ones, are regarded as most vulnerable to the rising temperature under global warming [27, 30, 31]. Significant impacts of the warming have been repeatedly shown in alpine plant [32-34] and animal communities [35-38]. In contrast, we know very little about temperature effects on alpine microbes [39-42], especially on ECM fungi. Although a few previous studies described ECM fungal communities in alpine habitats [42-45], these studies are all conducted at a local scale and none of them directly analyzed the effect of temperature. Given the critical roles of ECM fungi in forest ecosystems [46], relationships between temperature and below-ground ECM fungal communities could also provide important implications in the era of global warming.

Herein we investigated ECM fungal communities of monodominant $P$. pumila shrub forests on nine mountains across a $>1000 \mathrm{~km}$ geographic range and tested whether climate factors, including seasonal variations in temperature, significantly explained the variance in ECM fungal communities without the confounding effect of host species. In addition, potential temperature niches of individual ECM fungal species were inferred from the global records of the sequences with $\geq 97 \%$ similarities to the ones from the $P$. pumila forests and climate data at the geographical location of the sequence records. Then, we estimated the temperature of the observed communities by integrating the potential temperature niches of the individual fungal components and tested whether the estimated temperature was significantly correlated with actual temperature on the sites. The latter approach has rarely been applied to ECM fungal studies, although it could be an independent test that confirms the results of the former gradient analysis.

\section{Materials and methods}

\section{Study sites and soil sampling}

Study sites were established in P. pumila forests on nine mountains over the Japan archipelago (Table 1, Fig. 1a), including Mt. Norikura investigated in our previous study [45]. Geographic distance between study sites ranged from $50 \mathrm{~km}$ to over $1000 \mathrm{~km}$. All the study sites are located far above the tree line (Fig. S1), and the climates are characterized by low annual temperature and short snow-free growing seasons in general, yet the temperature and precipitation vary considerably across the sites. In winter, these sites are completely covered by snow up to $3 \mathrm{~m}$ in depth [47].

We generally followed Koizumi et al. [45] for soil sampling on the eight additional mountains. Two subplots were established in mature-shrub forests of $P$. pumila at each study site, where no other ECM tree was mixed. At a summer season of 2015 or 2016 (actual sampling date at each site is specified in Table 1 ), soil cores (each $5 \times 5 \times 10$ $\mathrm{cm}$ in depth) were excavated at 15 points with $>5 \mathrm{~m}$ apart in each subplot. Because of the cold climate, thick litter was accumulated on an immature mineral soil layer in these forests, producing two distinctive soil layers. Thus, we separately collected soil cores from the two soil layers at each sampling point, in brief 30 soil cores ( 15 from the litter and another 15 from the mineral soil layers) from each subplot. In total, 540 soil core samples were collected from the nine mountains. Collected samples were kept in plastic bags at $4{ }^{\circ} \mathrm{C}$ during transport to the laboratory.

\section{Fungal identification}

All ECM root tips were extracted from each soil sample, cleaned in tap water under a dissecting microscope (SZ2, Olympus, Co., Tokyo, Japan), and classified based on ECM morphology [19, 48]. Total DNA was extracted from an ECM root tip according to the modified CTAB method [48], with three replicates per morphotype for each soil sample. Internal transcribed spacer (ITS) regions were amplified using EmeraldAmp PCR Master Mix (Takara Bio Inc., Shiga, Japan) and a primer pair ITS-1F and LB-W [49]. For nonamplified samples, another primer pair ITS-1F and LA-W was used. Successfully amplified PCR products were 


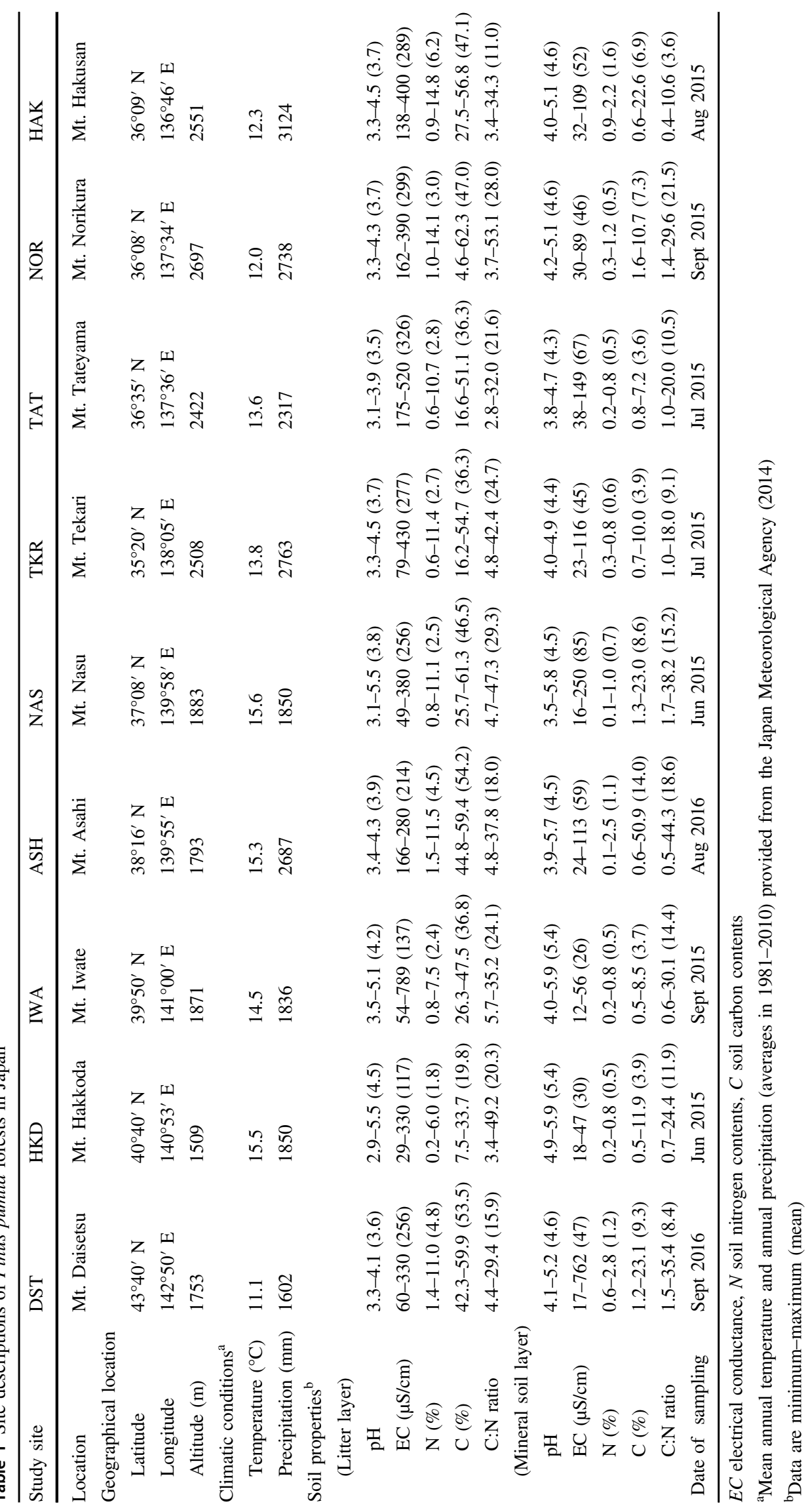




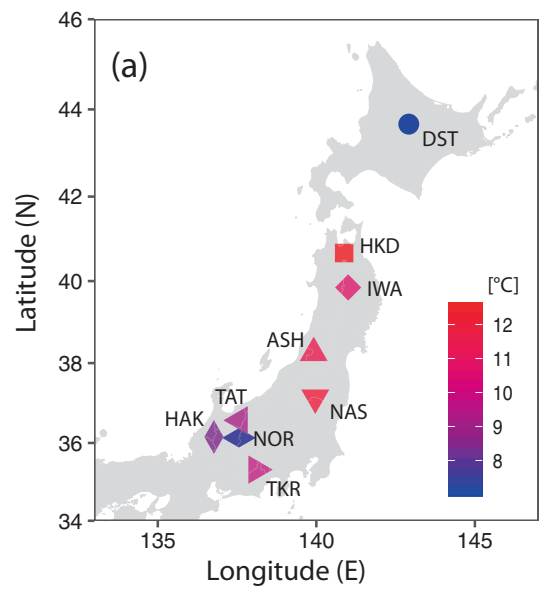

Fig. 1 Ectomycorrhizal fungal communities in alpine relict forests of Pinus pumila along with a temperature gradient. a Geographical locations of study sites and $\mathbf{b}$ nonmetric multidimensional scaling plot of the ectomycorrhizal fungal communities in litter (open) and mineral soil (filled) layers. Forward-selected variables in redundancy analysis

purified with exonuclease I and alkaline phosphatase (GE Healthcare, Chalfont St Giles, UK). Direct sequencing was performed using a 3730xl DNA Analyzer (Applied Biosystems, Foster City, CA, USA) with ITS-1 primer, or ITS4 primer if the first sequencing failed. After the careful quality check of sequence calls referring to the original chromatograms, $\geq 150$-bp high-quality sequences were assembled into operational taxonomic units (OTUs) based on $\geq 97 \%$ sequence similarity using ATGC software ver. 7 (Genetyx, Tokyo, Japan), as in Koizumi et al. [45]. Taxonomic assignment was performed for the obtained consensus and unassembled raw sequences with $\geq 350 \mathrm{bp}$, according to the BLAST results against the international nucleotide sequence database (INSD) and UNITE database. Sequences assigned to ECM fungal lineages defined by Tedersoo et al. [50] were used for the following analyses. Representative sequences of individual OTUs were deposited in GenBank under the accession numbers MK309945-310098.

\section{Environmental data collection}

Geographic locations of sampling points were recorded using a GPS (Garmin 62S, Garmin International, Olathe, KS, USA). Data of the mean of daily-mean, -minimum, and -maximum temperatures by month, the mean annual temperature, and monthly and annual precipitations at each study site, were retrieved from climate data at 30 (latitude) $\times 45$ (longitude) second spatial resolution provided by The Japan Meteorological Agency [51] (Table S1). Soil samples after removing ECM tips were dried at room temperature, sieved with $2 \mathrm{~mm}$ mesh, and used for $\mathrm{pH}$, electrical conductivity, $\mathrm{C}$, and $\mathrm{N}$ measurements as in

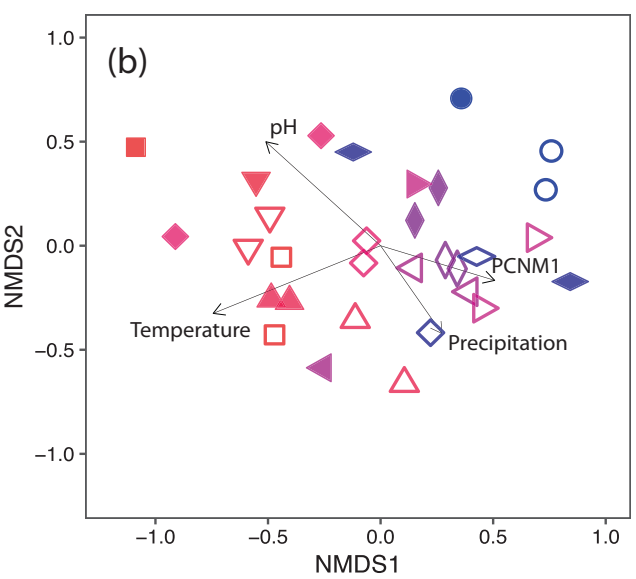

are shown by vectors on the plot. Color scale indicates the gradient of the mean of daily-minimum temperature in August from cold (blue) to warm (red) conditions. Different symbol shapes in (b) represent ectomycorrhizal fungal communities from different sites (a)

Koizumi and Nara [52]. These geographic, climate, and soil data are summarized in Table 1.

\section{Data analyses}

Chao2 species richness estimator, Shannon's and Simpson's diversity indices were used to evaluate ECM fungal diversity for each site. These values were calculated using the software EstimateS 9.1.0 [53], and were summarized in Table S2. OTU constructed by local assembly was treated as "species" in this study for the sake of simplicity. Singletons, species detected only in a single soil core, were removed from community analyses. If ECM roots were contained in less than half of the soil samples (specifically in the mineral soil layer at some sites), data from the two subplots at the same site were combined to maintain comparable data quality from other subplots. Frequencies of species occurrence (the number of soil samples containing each species per subplot) were Hellinger transformed and converted into a community distance matrix with Bray -Curtis distance. Differences in ECM fungal communities among study sites or soil layers were tested using the Adonis (permutational multivariate analysis of variance) function combined with a data dispersion test using the betadisper function in the vegan package [54]. Dissimilarities in ECM fungal communities were visualized on an ordination plot using the nonmetric multidimensional scaling (NMDS) method.

Distance-based redundancy analysis (db-RDA) was performed to quantify the relative importance of geographic, climate, and soil factors in explaining the variance in ECM community data [55]. Geographic location data (latitude and longitude) were transformed to principal 
coordinates of neighbor matrices (PCNM) vectors representing spatial patterns from broad to fine scales [56]. Monthly mean temperature variables were transformed to principal component vectors (hereafter designated as "PC.t"). Euclidean distance was used for the calculation of the dissimilarities in climate and soil conditions (i.e., $\mathrm{pH}$, electrical conductance, carbon and nitrogen contents, and $\mathrm{C} /$ $\mathrm{N}$ ratio) among subplots. Prior to db-RDA, explanatory variables for the best model were forward-selected based on the Akaike information criterion (AIC) from the geographic, climate, or soil factor. $R^{2}$ and its adjusted values $\left(R_{\text {adj }}^{2}\right)$ were used to quantify the contribution of the forward-selected variables. Additionally, the contribution of each nontransformed climate variable was quantified based on $R^{2}$ value to detect the most influential one to the communities. In this analysis, the mean of daily-mean, -minimum, and -maximum temperatures by month, those of the sampling month, the mean annual temperature, and monthly and annual precipitations were examined. All permutational statistical tests were performed with 9999 permutations using R software ver. 3.4.3 [57].

To analyze the response of individual ECM fungal species to the strongest climate variable in the db-RDA (the mean of daily-minimum temperature in August), linear and quadratic regressions were performed on the relative frequencies of each ECM fungal species detected from $\geq 5$ study sites. The Normality and homoscedasticity of residuals in the regressions were tested by Shapiro-Wilk normality test and Breusch-Pegan test, respectively. We also examined the relationship between ECM fungal richness per core and each climate variable used in the db-RDA by linear and quadratic regression analyses, where null soil samples (0 species/core) were included, after testing the regression assumptions as described above. The temperature-richness regression was applied separately to litter and mineral soil data, in addition to the combined data where the two soil layers per core point were merged. When both the linear and quadratic regressions were significant, we used the result of better regression coefficient.

\section{Potential temperature niches of ECM fungal components and estimated community temperature}

Temperature niches of ECM fungi were proposed to determine the distribution and community composition of ECM fungi along temperature gradient in Miyamoto et al. [26]. Here potential temperature niches of individual ECM fungal species detected were estimated from the global sequence records of the same species and associated climate data. Briefly, sequence records with $\geq 97 \%$ similarity against our query (i.e., a representative sequence of each species) were retrieved from UNITE and INSD. Geographic locations of the records were represented by the centroids of the countries because their exact positions were mostly unavailable. Mean of daily-mean, -minimum, and -maximum temperatures by month were retrieved from the WorldClim version 2.0 at $2.5 \mathrm{~min}$ spatial resolution [58]. Temperature data in the southern hemisphere were converted to those of the respective seasons in the northern hemisphere. A temperature niche of each fungal species was inferred as the range (from the minimum to maximum values) of a temperature variable (mean of daily-mean, -minimum, or -maximum temperature by month). It should be noted here that the inferred potential temperature niches are independent of our own dataset, because all sequence records from $P$. pumila forests in Japan were excluded before the temperature niche inference.

Temperature niches of all ECM fungal components determined from the global records were integrated after weighted by relative frequencies of the species to obtain a probability distribution of the given community along the temperature (see Fig. S2 for details). The expected value of the probability distribution was regarded as estimated temperature for the given community $\left(T_{\text {est }}\right)$. Correlation between $T_{\text {est }}$ and the actual temperature records of the site $\left(T_{\text {site }}\right)$ was tested for every pair of the same month by comparing the observed correlation coefficient value with a null probability distribution generated from random assignment of temperature niches among the fungal components. The correlation tests were separately performed for mean of daily-mean, -minimum, and -maximum temperatures. This test was based on the hypothesis that the distribution of each fungal species is determined by its temperature niche. If the hypothesis was not supported, the correlation will not become statistically significant. We admit that ECM fungal sequence records in the databases are geographically biased and not exhaustive [50], and coarse positioning of the records would further increase random errors in estimating temperature niches. But these potential errors do not increase the type I error (false positive) in the above correlation test, rather making the test conservative.

\section{Results}

\section{General description of ECM fungal communities in $P$. pumila forests}

ECM fungi were confirmed in 263 (27-30 out of 30 per site) and 156 (5-25) soil cores of litter and mineral soil layers, respectively. Totally, 2904 and 1230 ECM tips from litter and mineral soil layers, respectively, were subjected to DNA extraction. We successfully obtained 2870 highquality sequences from $80.4 \%$ cumulative ECM morphotypes, including 443 sequences used in Koizumi et al. [45]. 
Table 2 Relative contributions of potential factors to ectomycorrhizal fungal composition in Pinus pumila forests in Japan

\begin{tabular}{|c|c|c|c|c|c|c|c|c|c|}
\hline \multirow[t]{2}{*}{ Factor } & \multicolumn{3}{|l|}{ Litter + Mineral soil } & \multicolumn{3}{|l|}{ Litter } & \multicolumn{3}{|l|}{ Mineral soil } \\
\hline & Forward-selected variables & $R^{2}$ & $R_{\text {adj }}^{2}$ & Forward-selected variables & $R^{2}$ & $R_{\text {adj }}^{2}$ & Forward-selected variables & $R^{2}$ & $R_{\text {adj }}^{2}$ \\
\hline Spatiality & PCNM1, 2, 3, 7, 6 & 0.316 & 0.179 & PCNM2, 1 & 0.261 & 0.163 & PCNM1, 2 & 0.308 & 0.170 \\
\hline Climate & PC.t1, Prec, t5, t4, t6 & 0.416 & 0.239 & PC.t1, Prec, t5 & 0.368 & 0.232 & PC.t1, t2 & 0.300 & 0.160 \\
\hline Soil & $\mathrm{pH}, \mathrm{C} / \mathrm{N}$ ratio & 0.155 & 0.094 & $\mathrm{pH}$ & 0.133 & 0.079 & $\mathrm{pH}$ & 0.150 & 0.073 \\
\hline Total & & 0.666 & 0.374 & & 0.544 & 0.296 & & 0.585 & 0.288 \\
\hline
\end{tabular}

$R^{2} a d j R^{2}$ value adjusted by number of variables, PC.t principal component axis originated from the mean of daily-mean temperatures by month, Prec annual precipitation

After removing OTUs represented by short sequences ( $<350 \mathrm{bp}$ ), we identified 154 species that were assigned to ECM fungal lineages (Table S3). The most species-rich lineage was /cortinarius (36 spp.), followed by /russulalactarius (23 spp.) and /tomentella-thelephora (23 spp.). Litter and mineral soil layers contained 132 spp. and 88 spp., respectively. The most dominant lineage in the litter layer was /cortinarius (23.3\%), followed by /suillusrhizopogon (20.5\%) and /russula-lactarius (19.7\%). In the mineral soil layer, /suillus-rhizopogon (23.3\%) and /russulalactarius $(22.4 \%)$ were the dominant lineages. According to the sequence database, 102 of 154 species $(84.4 \%)$ had records in other Holarctic regions, i.e., Europe, Russia, North America, Northern Africa, or the Middle East (Table S3).

\section{Differences in ECM fungal composition}

Mineral soil samples in DST, HKD, NAS, TAT or TKR contained few ECM roots ( $<7$ cores/subplot), making quantitative community analyses difficult. Thus, the community data in mineral soils from the two subplots were pooled for the site before community analyses. ECM fungal composition was significantly different among study sites $\left(F=2.78, R^{2}=0.50, P<0.01\right)$ and between soil layers $\left(F=2.43, R^{2}=0.08, P<0.01\right)$ without significant differences in data heterogeneity (site: $F=0.54, P=0.81$; soil: $F=2.58, P=0.12$ ).

\section{Contributions of abiotic factors to ECM fungal communities}

Climate factors explained the largest variance $\left(R_{\text {adj: }}^{2}: 23.9 \%\right)$ of ECM fungal community data, followed by spatial $(17.9 \%)$ and soil factors $(9.4 \%)$ in the entire dataset (Table 2, Fig. 1b). In total, $37.4 \%$ of the variance in the community data was explained by the forward-selected variables. Although all monthly temperature variables tested explained the community variance at statistically significant levels, those of summer seasons had higher contributions (Fig. 2). In particular, the mean of daily-minimum

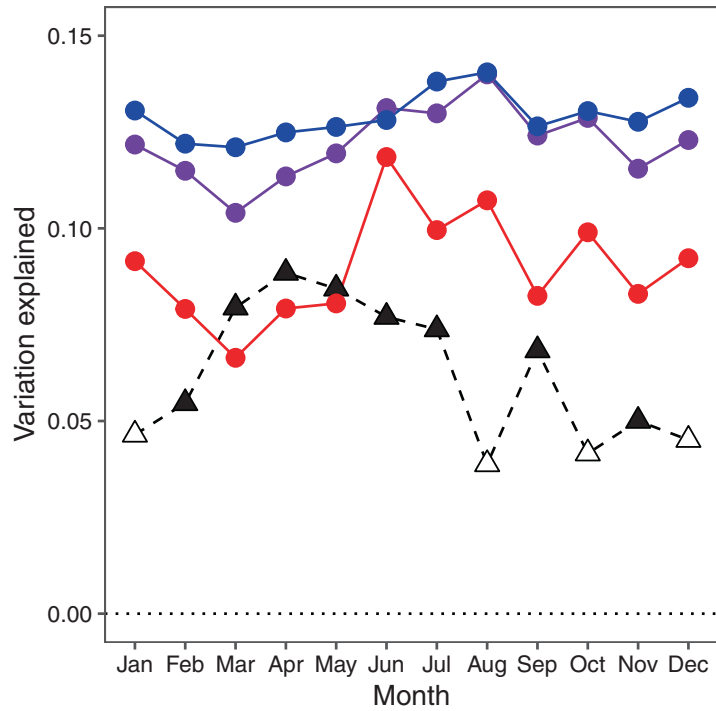

Fig. 2 Contribution of climate variables to ectomycorrhizal fungal composition in alpine relict forests of Pinus pumila. Colors indicate seasonal variations of monthly mean of daily-mean (purple), -minimum (blue) and -maximum (red) temperatures and monthly precipitation (black). Symbols and lines indicate temperatures (circle with solid line) and precipitation (triangle with dashed line). Filled symbols indicate significant contributions $(P<0.05)$. All climate data used in this figure were retrieved from the Japan Meteorological Agency

temperature in August was the strongest $\left(R^{2}: 14.0 \%\right)$. Temperature variables of the sampling months were still significant but explained lower proportions of the variance $\left(R^{2}: 6.8-7.7 \%\right)$. Compared to these temperature variables, community variance explained by monthly precipitation was generally lower and sometimes nonsignificant (Fig. 2).

When the db-RDA was separately performed for litter layer communities, the contribution of climate factors was $23.2 \%$, which was far larger than that of spatial and soil factors (Table 2). All monthly temperature variables examined significantly explained the variance of ECM fungal communities (Fig. S3a). Especially, the mean of daily-minimum temperature in August alone explained $21.9 \%$ of the variance, which was larger than that for the combined dataset of the two soil layers $(14.0 \%)$. In the mineral soil layer, community variance was less explained by climate factors $(16.0 \%)$ than spatial factors $(17.0 \%)$ 
(Table 2). However, most temperature variables examined were still statistically significant in structuring the communities (Fig. S3b). The mean of daily-mean temperature in August was the most influential single factor examined (19.6\%), but its contribution to the community variance was less obvious than that observed in the litter communities $(21.8 \%)$. Contributions of individual variables used in $\mathrm{db}$ RDA are summarized in Table S4 (those of monthly variables are in Fig. 2 and Fig. S3).

\section{Species occurrence in response to a temperature gradient}

Of the 23 ECM fungal species that occurred at $\geq 5$ study sites, eight species significantly changed their relative frequency with the mean of daily-minimum temperature in August (Fig. 3). Four and two species were assigned to /cortinarius and /suillus-rhizopogon lineages, respectively. The other two species belonged to /russula-lactarius and /tomentella-thelephora lineages. In regression analysis, variances of residuals were heteroscedastic for Cortinarius acutus sp. $1(P=0.03)$ and Russula emetica $(P=0.02)$. However, we accepted these regression results because the observed heteroscedasticities likely arose from zero variance because of their complete absence in warmer sites (Fig. 3). All the /cortinarius species were less frequent in warmer sites, whereas /suillus-rhizopogon species increased their frequencies there. In total, five and three species showed significant negative and positive associations, respectively, with the temperature.

\section{Effect of temperatures on ECM fungal richness}

ECM fungal richness per core was mostly explained by the mean of daily-minimum temperature in May by quadratic regression $\left(R^{2}=0.73, P<0.01\right)$, where the richness was high at the middle and low at both ends of the temperature range across the study sites (Fig. 4). The mean of dailyminimum temperatures in June and May were the most effective variable in explaining ECM fungal richness per core from the litter $\left(R^{2}=0.69, P<0.01\right.$, Fig. S4a) and mineral soil layers $\left(R^{2}=0.58, P<0.01\right.$, Fig. $\left.\mathrm{S} 4 \mathrm{~b}\right)$, respectively. No deviation from the regression assumptions (i.e., normality and homoscedasticity of variances) was found in any tests above $(P>0.1)$. Sampling months did not significantly affect ECM fungal richness $(P>0.1)$.

\section{Potential temperature niches of ECM fungal components and estimated community temperature}

Of 154 ECM fungal species detected in this study, 115 had sequence records in other geographic areas (Fig. S5, Table S5). Based on the locations of the records and climate data from WorldClim, temperature ranges of the 115 ECM fungal species were compiled. Using these temperature ranges of individual ECM fungi, we estimated the temperature for each observed community $\left(T_{\text {est }}\right)$ as detailed in Fig. S2.

Correlation coefficients between the actual temperature records of the sites $\left(T_{\text {site }}\right)$ and $T_{\text {est }}$ were generally higher in summer seasons (April-July) than other seasons for all types of temperature variables (Fig. 5a). The highest correlation coefficient was obtained from the mean temperature in June $(R=0.60, P=0.02$, Fig. $5 b)$.

\section{Discussion}

In total, 154 ECM fungal species were identified from 540 soil samples collected from 9 mountains over $>1000$ $\mathrm{km}$ in the Japan archipelago, representing the most extensive and comprehensive dataset of ECM fungi in alpine regions. Because previous studies on alpine ECM fungi are mostly descriptive and are restricted to a local site [45, 59-63], none of them examined the climate effect sufficiently. Alpine ecosystems, and more specifically alpine plant and animal communities, are regarded as most susceptible to the rising temperature under global warming [64-67], but its impact on below-ground ECM fungi remained unknown. This was largely caused by the lack of comprehensive community datasets for alpine ECM fungi. Given the critical roles of ECM fungi in forest ecosystems [46], we urgently need to accumulate community data for alpine ECM fungi, ideally as comparable to alpine plant and animal data [41, 68]. The dataset developed in this study is an important step in this direction.

Herein we confirmed that ECM fungal communities in monospecific alpine forests were structured more by climate factors than spatial and soil factors. Several previous studies also suggested significant temperature effects on ECM fungal communities [13-16], but the observed temperature effects in these studies were not necessarily isolated from the covarying effects of host species and coexisting plants. Because our data were collected from the same vegetation type dominated by a single host species, it is clear that temperature could be a strong driver in structuring ECM fungal communities without the effects of host species and coexisting plants. Host intraspecific variations, and physiological variations potentially within a species, might potentially account for ECM fungal variation [69-71], but population genetic structures of $P$. pumila examined by isozymes [72] or microsatellites (Koizumi et al. in preparation) are determined largely by geographical distance, which corresponds to spatial factors (PCNM vectors) in this paper and does not explain the variance in ECM fungal communities in this study. 
Fig. 3 Relative frequency of each ectomycorrhizal fungal species changes along summer temperature (mean of dailyminimum temperature in August) in alpine Pinus pumila forests, Japan. Fungal lineages are shown in different colors.

Gray zones indicate $95 \%$

confidence intervals
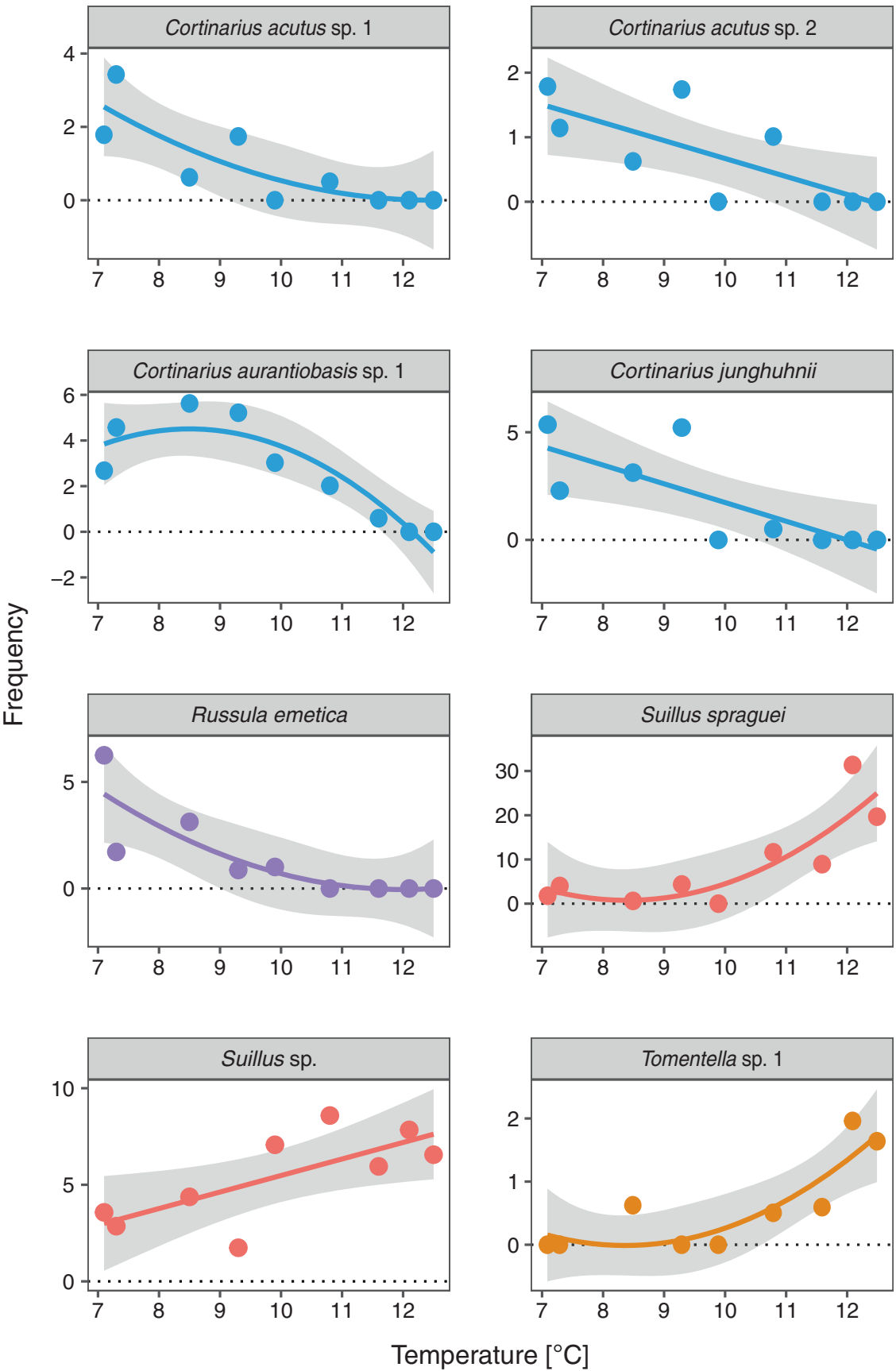

While none of the previous studies examined the effect of seasonal temperature variations on ECM fungal communities, our results clearly indicate that temperature in summer seasons has a greater effect than that of other seasons. Soil surface temperature under $P$. pumila forests is almost the same as the air temperature in summer seasons [73]. Under the typical thick litter layer of $P$. pumila forests (at $15 \mathrm{~cm}$ soil depth), soil temperature still shows a seasonal pattern similar to that of the air temperature, but within a smaller range with a short time lag, e.g., the maximum daily mean air temperature $\left(20^{\circ} \mathrm{C}\right)$ was recorded at the end of
July but that of the soil $\left(14^{\circ} \mathrm{C}\right)$ appeared in mid-August [47]. Therefore, in summer, the air temperature directly affects soil temperature, which may affect ECM fungal physiology and become a selection pressure in relation to inherent temperature niches of ECM fungal components.

The strong effect of summer temperature may also be related to the site conditions of the studied alpine relict forests, where soil is frozen during winter seasons that extend about a half year [47]. Moreover, soil temperature in winter is not directly affected by air temperature in these sites because of the snow that completely covers the host. In 
fact, daily mean air temperature goes below $-20^{\circ} \mathrm{C}$, while soil temperature within the litter layer at $5 \mathrm{~cm}$ depth is stable around $-1{ }^{\circ} \mathrm{C}$ [47]. Given the small variation in soil temperature under snow coverage and inactivated host and ECM fungi in the humid alpine ecosystem during winter seasons, environmental selection pressures would necessarily become higher in short summer seasons. The observed effect of summer temperature might be potentially related to our sampling design, in which one snapshot sampling per site was conducted during summer seasons. Seasonal changes in ECM fungal communities have been shown in some temperate forests $[74,75]$. Although we found no

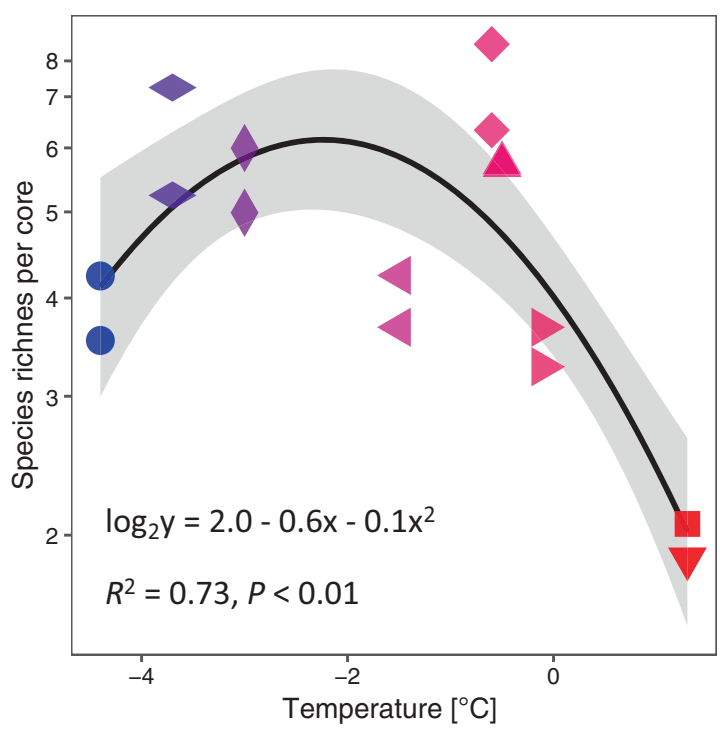

Fig. 4 Relationship between temperature (mean of daily-minimum temperature in May) and species richness (richness per soil core) of ectomycorrhizal fungi in alpine Pinus pumila forests in Japan. Color scale indicates the temperature gradient as in Fig. 1. Symbol shapes are the same as Fig. 1. Gray zone indicates $95 \%$ confidence interval

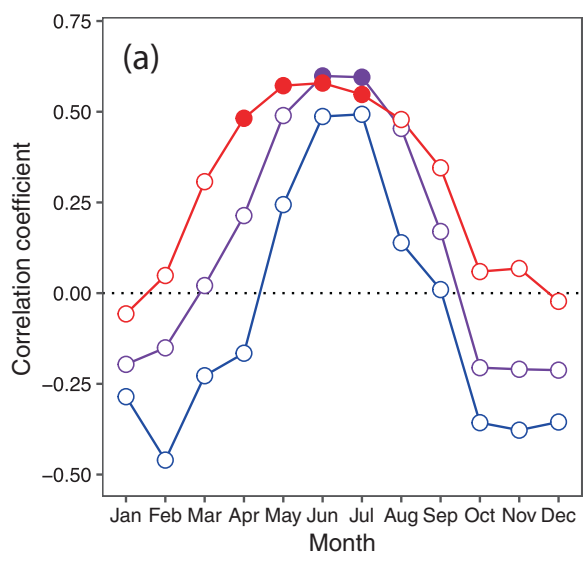

Fig. 5 Correlation between actual site temperature $\left(T_{\text {site }}\right)$ and deduced temperature $\left(T_{\text {est }}\right)$ based on the global records of ectomycorrhizal fungi. a Correlation coefficients between $T_{\text {site }}$ and $T_{\text {est }}$ using temperature variables of the same month; monthly mean of daily-mean (purple), -minimum (blue) and -maximum (red) temperatures. Filled significant effect of sampling month during the summer seasons, ECM fungal communities in other seasons might be determined by different factors, e.g. winter ECM fungal communities might be determined by winter temperature or something. This would worth further testing hypothetically, but not in our study sites, where sampling in winter seasons is physically impossible due to the thick snow coverage, frozen soil, extremely cold temperature, and prohibited access for safety reasons. We also do not think ECM fungal communities in the frozen soil deserve further investigation, given that they are virtually dormant and inactive physiologically and ecologically. Instead, it would be interesting and deserve further research to confirm whether the strong effect of summer temperature on ECM fungal communities holds true in other seasons and different ecosystems, ideally using seasonal sampling designs.

The effect of summer temperature on alpine ECM fungal communities was more obvious in the litter soil layer (21.9\% variance explained) than in the deeper mineral soil layer (19.6\%). Given soil temperature is more stable in deeper subsoil [76, 77], the observed difference further suggests direct effects of temperature on ECM fungi. Shoot growth [78] and photosynthesis/respiration activities [79] of $P$. pumila are also affected by temperature, which might potentially affect ECM communities. Such indirect temperature effect through host activity may partly account for the variance in ECM fungal communities. But the difference between the two soil layers within a site could not be explained by the host physiological changes, because ECM roots in both soil layers would be associated with the same host trees under the same air temperature in our sampling design.

It is well known that ECM fungal composition changes with the depth of soil [45, 80-86], while the pattern is

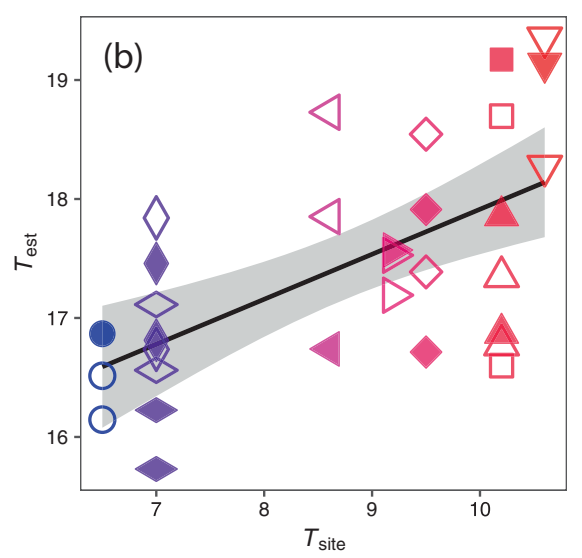

symbols indicate significant correlations $(P<0.05)$. b Correlation between $T_{\text {site }}$ and $T_{\text {est }}$ using mean monthly temperature in June. Color scale indicates the temperature gradient as in Fig. 1. Symbols are the same as Fig. 1. Gray zone indicates $95 \%$ confidence interval 
usually attributed to the difference in the amount and quality of organic matter. However, if temperature would directly affect ECM fungal communities, vertical distribution of ECM fungi is not solely structured by the soil factors and may be partly attributed to temperature.

The effect of summer temperature on ECM fungi was also confirmed at the species level. Specifically, all of the four Cortinarius species examined decreased their frequencies with increasing temperature in early summer (Fig. 3). Interestingly, these Cortinarius species were far more frequent in the litter soil than in mineral soil (data not shown). In general, Cortinarius species proliferate in an organic soil layer accumulated under low temperature climates [24, 87-89], probably because of Mn-peroxidases that enable effective decomposition of recalcitrant organic matter [90]. Thus, the advantage of Cortinarius may decrease under increased temperatures, which activate decomposing fungi and may decrease the frequencies of Cortinarius. Similarly, $R$. emetica significantly decreased their frequencies with increasing temperature (Fig. 3). Although it is not surprising to see these cold-adapted fungi in the relict alpine ecosystems, fewer species, including two Suillus spp. and Tomentella sp. 1, increased their frequencies with temperature increases. They may have come from forests at lower altitudes and been replacing coldadapted ECM fungi. In any case, our results strongly support the existence of temperature niches of ECM fungal species and its interspecific variations [26].

All the above results from gradient analyses suggest that ECM fungal distribution and resultant communities are related to temperature, yet we are not sure whether the observed pattern reflected temperature niches of individual fungal components. Then, we inferred potential temperature niches of the observed ECM fungal species independently of our own data, using global sequence records and corresponding climate data. Based on these potential temperature niches of individual ECM fungal components, we estimated the temperature for the observed communities, i.e., $T_{\text {est }}$, and found that it was significantly correlated with the actual temperature of the sites $\left(T_{\text {site }}\right)$, specifically those in summer seasons. This result supports the hypothesis that ECM fungal communities are determined by temperature niches of the components. Because the two independent analyses gave correspond results, we are confident that summer temperature could be an important determinant of ECM fungal communities.

Even though the latter approach using global sequence databases provides strong and valuable inferences, especially when similar sequence matches are abundant in the databases as in this study, we should be cautious about current limitations. Available ECM fungal records in the sequence database are still sporadic geographically and never list all species in a region even where ECM fungal communities were studied. Thus, the potential temperature niches inferred from the available sequence records include some uncertainty. Moreover, coarse geographical positioning of the sequence records may further increase the uncertainty in the temperature niches inferred. Such uncertainty brings random errors, which increase statistical noise and reduce the statistical power of the correlation tests. Despite such conservative testing, we still found significant correlations between the actual temperature of the sites and the temperature estimated from the inferred potential temperature niches in summer seasons (Fig. 5). The correlation would not be significant if the temperature niche hypothesis was not supported, or if the random errors were too large. Thus, we think temperature niches of ECM fungi, as well as their distribution and composition, would be largely determined by summer temperature. With further enrichment of the database by additional ECM fungal records and development of direct links between sequence records and precise climate data in the future, temperature niche inference would be much more accurate. This would not only increase the statistical power of the correlation test, but also enable detailed prediction of community changes along the temperature gradient.

Temperature was also shown to affect ECM fungal richness, which showed a unimodal pattern along the earlysummer temperature gradient with a large regression coefficient (Fig. 4). Because temperature niches of individual ECM fungal species are finite values, their niches would inherently overlap most in the mid temperature range, as similar to the mid-domain effect $[12,26]$. But Miyamoto et al. [26] showed that ECM fungal richness per core linearly decreased with mean annual temperature from cool temperate to subtropical forests. Because their study did not include extremely cold sites like alpine $P$. pumila forests in this study, the richness pattern of ECM fungi would become unimodal along temperature range of the entire globe [91, 92].

Finally, our results would provide some implications for ecosystem changes under global warming, which is the global-scale long-term rise in temperature in definition. Although the global warming induces some other climate changes (e.g., precipitation and its interregional variations), temperature itself, especially summer temperature, was the strongest factor in structuring ECM fungal communities in our analyses including other factors like precipitation (snow in winter). Thus, the expected rise in summer temperature under global warming [93, 94] would have a significant impact on ECM fungal communities. It should be also noted here that the temperature effect in ECM fungal communities was significant with no obvious change in above-ground vegetation. Therefore, changes in below-ground microbial communities by global warming may have already been 
occurring unnoticeably, and potentially contributing to the resilience of above-ground vegetation.

In summary, we found that summer temperature significantly accounts for the variability in ECM fungal communities in alpine relict forests, where the effect of host species is excluded. The observed distribution of ECM fungal species corresponded with their inherent temperature niches, which were estimated from the global sequence records and associating climate data. Frequency of some cold-adapted fungal lineages significantly decreased with temperature. These results indicates summer temperature, and probably corresponding soil temperature, could be an important factor in structuring ECM fungal communities, although further research would be needed to conclude that temperature directly selects ECM fungal species. Because ECM fungal communities changed along the temperature gradient without any noticeable change in the above-ground vegetation in this study, these microbes may be the key to ecosystem resilience to changing temperature, possibly alleviating the impact of global warming.

Acknowledgements The authors thank Masahira Hattori and Kenshiro Oshima for assistance in sequencing; Masao Murata for technical assistance; staffs of the Norikura Observatory for assistance in field; The Ministry of the Environment and the Forest Agency of Japan for the permissions of field researches. This work was supported by JSPS KAKENHI grant numbers 25660115, 16J07343, 15H02449, and 18H03955, and the research grant from Institute for Fermentation.

\section{Compliance with ethical standards}

Conflict of interest The authors declare that they have no conflict of interest.

Publisher's note Springer Nature remains neutral with regard to jurisdictional claims in published maps and institutional affiliations.

\section{References}

1. Smith SE, Read DJ. Mycorrhizal symbiosis, 3rd ed. London: Academic Press; 2008.

2. Baxter JW, Dighton J. Ectomycorrhizal diversity alters growth and nutrient acquisition of grey birch (Betula populifolia) seedlings in host-symbiont culture conditions. New Phytol. 2001;152:139-49.

3. Mosca E, Montecchio L, Sella L, Garbaye J. Short-term effect of removing tree competition on the ectomycorrhizal status of a declining pedunculate oak forest (Quercus robur L.). Ecol Manag. 2007;244:129-40.

4. Boyle CD, Hellenbrand KE. Assessment of the effect of mycorrhizal fungi on drought tolerance of conifer seedlings. Can J Bot. 1991;69:1764-71.

5. Parke JL, Linderman RG, Black $\mathrm{CH}$. The role of ectomycorrhizas in drought tolerance of Douglas-fir seedlings. New Phytol. 1983;95:83-95.

6. Chakravarty P, Unestam T. Differential influence of ectomycorrhizae on plant growth and disease resistance in Pinus sylvestris seedlings. J Phytopathol. 1987;120:104-20.
7. Duchesne LC, Peterson RL, Ellis BE. Interaction between the ectomycorrhizal fungus Paxillus involutus and Pinus resinosa induces resistance to Fusarium oxysporum. Can $\mathrm{J}$ Bot. 1988;66:558-62.

8. Sylvia DM, Sinclair WA. Phenolic compounds and resistance to fungal pathogens induced in primary roots of Douglas fir seedlings by the ectomycorrhizal fungus Laccaria laccata. Phytopathology. 1983;73:390-7.

9. Read DJ, Perez-Moreno J. Mycorrhizas and nutrient cycling in ecosystems - a journey towards relevance? New Phytol. 2003;157:475-92.

10. Glassman SI, Peay KG, Talbot JM, Smith DP, Chung JA, Taylor JW, et al. A continental view of pine-associated ectomycorrhizal fungal spore banks: a quiescent functional guild with a strong biogeographic pattern. New Phytol. 2015;205:1619-31.

11. Lilleskov EA, Bruns TD, Horton TR, Taylor DL, Grogan P. Detection of forest stand-level spatial structure in ectomycorrhizal fungal communities. FEMS Microbiol Ecol. 2004;49:319-32.

12. Miyamoto $Y$, Nakano T, Hattori M, Nara K. The mid-domain effect in ectomycorrhizal fungi: range overlap along an elevation gradient on Mount Fuji, Japan. ISME J. 2014;8:1739-46.

13. Bahram M, Põlme S, Kõljalg U, Zarre S, Tedersoo L. Regional and local patterns of ectomycorrhizal fungal diversity and community structure along an altitudinal gradient in the Hyrcanian forests of northern Iran. New Phytol. 2012;193:465-73.

14. Jarvis S, Woodward S, Alexander IJ, Taylor AFS. Regional scale gradients of climate and nitrogen deposition drive variation in ectomycorrhizal fungal communities associated with native Scots pine. Glob Change Biol. 2013;19:1688-96.

15. Matsuoka S, Mori AS, Kawaguchi E, Hobara S, Osono T. Disentangling the relative importance of host tree community, abiotic environment and spatial factors on ectomycorrhizal fungal assemblages along an elevation gradient. FEMS Microbiol Ecol. 2016;92:fiw044.

16. Miyamoto Y, Sakai A, Hattori M, Nara K. Strong effect of climate on ectomycorrhizal fungal composition: evidence from range overlap between two mountains. ISME J. 2015;9:1870-9.

17. Peay KG, Kennedy PG, Davies SJ, Tan S, Bruns TD. Potential link between plant and fungal distributions in a dipterocarp rainforest: community and phylogenetic structure of tropical ectomycorrhizal fungi across a plant and soil ecotone. New Phytol. 2010;185:529-42.

18. Toljander JF, Eberhardt U, Toljander YK, Paul LR, Taylor AFS. Species composition of an ectomycorrhizal fungal community along a local nutrient gradient in a boreal forest. New Phytol. 2006;170:873-83.

19. Ishida TA, Nara K, Hogetsu T. Host effects on ectomycorrhizal fungal communities: insight from eight host species in mixed conifer-broadleaf forests. New Phytol. 2007;174:430-40.

20. Kennedy PG, Mielke LA, Nguyen NH. Ecological responses to forest age, habitat, and host vary by mycorrhizal type in boreal peatlands. Mycorrhiza . 2018;28:315-28.

21. Morris MH, Perez-Perez MA, Smith ME, Bledsoe CS. Influence of host species on ectomycorrhizal communities associated with two co-occurring oaks (Quercus spp.) in a tropical cloud forest. FEMS Microbiol Ecol. 2009;69:274-87.

22. Nguyen NH, Williams LJ, Vincent JB, Stefanski A, CavenderBares J, Messier C, et al. Ectomycorrhizal fungal diversity and saprotrophic fungal diversity are linked to different tree community attributes in a field-based tree experiment. Mol Ecol. 2016;25:4032-46.

23. Jarvis SG, Woodward S, Taylor AFS. Strong altitudinal partitioning in the distributions of ectomycorrhizal fungi along a short (300 m) elevation gradient. New Phytol. 2015;206:1145-55.

24. Scattolin L, Lancellotti E, Franceschini A, Montecchio L. The ectomycorrhizal community in Mediterranean old-growth 
Quercus ilex forests along an altitudinal gradient. Plant Biosyst. 2014;148:74-82.

25. Deslippe JR, Hartmann M, Mohn WW, Simard SW. Long-term experimental manipulation of climate alters the ectomycorrhizal community of Betula nana in Arctic tundra. Glob Change Biol. 2011;17:1625-36.

26. Miyamoto Y, Terashima Y, Nara K. Temperature niche position and breadth of ectomycorrhizal fungi: reduced diversity under warming predicted by a nested community structure. Glob Change Biol. 2018;24:5724-37.

27. Horikawa M, Tsuyama I, Matsui T, Kominami Y, Tanaka N. Assessing the potential impacts of climate change on the alpine habitat suitability of Japanese stone pine (Pinus pumila). Landsc Ecol. 2009;24:115-28.

28. Takahashi K. Effects of climatic conditions on shoot elongation of alpine dwarf pine (Pinus pumila) at its upper and lower altitudinal limits in central Japan. Arct Antarct Alp Res. 2003;35:1-7.

29. Yoshino MM. Altitudinal vegetation belts of Japan with special reference to climatic conditions. Arct Alp Res. 1978;10:449-56.

30. Muhlfeld CC, Giersch JJ, Hauer FR, Pederson GT, Luikart G, Peterson DP, et al. Climate change links fate of glaciers and an endemic alpine invertebrate. Clim Change. 2011;106:337-45.

31. Vanneste T, Michelsen O, Graae BJ, Kyrkjeeide MO, Holien H, Hassel K, et al. Impact of climate change on alpine vegetation of mountain summits in Norway. Ecol Res. 2017;32:579-93.

32. Hedhly A, Hormaza JI, Herrero M. Global warming and sexual plant reproduction. Trends Plant Sci. 2009;14:30-6.

33. Körner C, Basler D. Phenology under global warming. Science. 2010;327:1461-2.

34. Saxe H, Cannell MGR, Johnsen B, Ryan MG, Vourlitis G. Tree and forest functioning in response to global warming. New Phytol. 2001;149:369-99.

35. Dighton J, Mason PA. Mycorrhiza dynamics during forest tree development. In: Moore D, Casselton LA, Woods DA, Franklin JC, editors. Developmental biology of higher fungi. Cambridge: Cambridge University Press; 1985. p. 117-39.

36. Gobbi M, Fontaneto D, De Bernardi F. Influence of climate changes on animal communities in space and time: the case of spider assemblages along an alpine glacier foreland. Glob Change Biol. 2006;12:1985-92.

37. Hogg ID, Williams DD. Response of stream invertebrates to a global-warming thermal regime: an ecosystem-level manipulation. Ecology. 1996;77:395-407.

38. Root TL, Price JT, Hall KR, Schneider SH, Rosenzweig C, Pounds JA. Fingerprints of global warming on wild animals and plants. Nature. 2003;421:57-60.

39. Brunner I, Frey B, Hartmann M, Zimmermann S, Graf F, Suz LM, et al. Ecology of alpine macrofungi-combining historical with recent data. Front Microbiol. 2017;8:2066.

40. Han QS, Huang J, Long DF, Wang XB, Liu JJ. Diversity and community structure of ectomycorrhizal fungi associated with Larix chinensis across the alpine treeline ecotone of Taibai Mountain. Mycorrhiza. 2017;27:487-97.

41. Ni YY, Yang T, Zhang KP, Shen CC, Chu HY. Fungal communities along a small-scale elevational gradient in an alpine tundra are determined by soil carbon nitrogen ratios. Front Microbiol. 2018;9:1815.

42. Ryberg M, Larsson E, Molau U. Ectomycorrhizal diversity on Dryas octopetala and Salix reticulata in an alpine cliff ecosystem. Arct Antarct Alp Res. 2009;41:506-14.

43. Clemmensen KE, Michelsen A. Integrated long-term responses of an arctic-alpine willow and associated ectomycorrhizal fungi to an altered environment. Can J Bot. 2006;84:831-43.

44. Kernaghan G, Harper KA. Community structure of ectomycorrhizal fungi across an alpine/subalpine ecotone. Ecography. 2001; 24:181-8.
45. Koizumi T, Hattori M, Nara K. Ectomycorrhizal fungal communities in alpine relict forests of Pinus pumila on Mt. Norikura, Japan. Mycorrhiza. 2018;1:1-17.

46. Koide RT, Fernandez C, Malcolm G. Determining place and process: functional traits of ectomycorrhizal fungi that affect both community structure and ecosystem function. New Phytol. 2014;201:433-9.

47. Takahashi K, Nagano S, Maruta E. Relationships between vegetation cover and seedling distribution of the alpine dwarf pine Pinus pumila on Mt. Norikura, central Japan. Vegetation Sci. 2005;22:147-52.

48. Nara K, Nakaya H, Wu BY, Zhou ZH, Hogetsu T. Underground primary succession of ectomycorrhizal fungi in a volcanic desert on Mount Fuji. New Phytol. 2003;159:743-56.

49. Tedersoo L, Jairus T, Horton BM, Abarenkov K, Suvi T, Saar I, et al. Strong host preference of ectomycorrhizal fungi in a Tasmanian wet sclerophyll forest as revealed by DNA barcoding and taxon-specific primers. New Phytol. 2008;180:479-90.

50. Tedersoo L, May TW, Smith ME. Ectomycorrhizal lifestyle in fungi: global diversity, distribution, and evolution of phylogenetic lineages. Mycorrhiza. 2010;20:217-63.

51. The Japan Meteorological Agency. Mesh average 2010. Tokyo, Japan; 2014

52. Koizumi T, Nara K. Communities of putative ericoid mycorrhizal fungi isolated from alpine dwarf shrubs in Japan: effects of host identity and microhabitat. Microbes Environ. 2017;32:147-53.

53. Colwell RK, Chao A, Gotelli NJ, Lin SY, Mao CX, Chazdon RL, et al. Models and estimators linking individual-based and samplebased rarefaction, extrapolation and comparison of assemblages. $\mathrm{J}$ Plant Ecol. 2012;5:3-21.

54. Oksanen JBG, Kindt R, Legendre P, O'Hara B, Simpson GL, Solymos $\mathrm{P}$, et al. Package 'vegan' community ecology package. $\mathrm{R}$ Package Version 1.17-2. 2010.

55. Peres-Neto PR, Legendre P, Dray S, Borcard D. Variation partitioning of species data matrices: estimation and comparison of fractions. Ecology. 2006;87:2614-25.

56. Borcard D, Legendre P, Avois-Jacquet C, Tuomisto H. Dissecting the spatial structure of ecological data at multiple scales. Ecology . 2004;85:1826-32.

57. R Development Core Team. R: a language and environment for statistical computing. [WWW document] URL: http://www.Rproject.org. Vienna, Austria: R Foundation for Statistical Computing; 2016.

58. Fick SE, Hijmans RJ. WorldClim 2: new 1-km spatial resolution climate surfaces for global land areas. Int J Climatol. 2017;37: 4302-15.

59. Gao Q, Yang ZL. Ectomycorrhizal fungi associated with two species of Kobresia in an alpine meadow in the eastern Himalaya. Mycorrhiza . 2010;20:281-7.

60. Krpata D, Muhlmann O, Kuhnert R, Ladurner H, Gobl F, Peintner U. High diversity of ectomycorrhizal fungi associated with Arctostaphylos uva-ursi in subalpine and alpine zones: potential inoculum for afforestation. Ecol Manag. 2007;250:167-75.

61. Mühlmann O, Bacher M, Peintner U. Polygonum viviparum mycobionts on an alpine primary successional glacier forefront. Mycorrhiza . 2008;18:87-95.

62. Mundra S, Bahram M, Tedersoo L, Kauserud H, Halvorsen R, Eidesen PB. Temporal variation of Bistorta vivipara-associated ectomycorrhizal fungal communities in the High Arctic. Mol Ecol. 2015;24:6289-302.

63. Oberkofler I, Peintner U. Detection of soil fungal communities in an alpine primary successional habitat: does pooling of DNA extracts affect investigations? Ann Microbiol. 2008;58:585-95.

64. Johnson DM, Buntgen U, Frank DC, Kausrud K, Haynes KJ, Liebhold AM, et al. Climatic warming disrupts recurrent alpine insect outbreaks. Proc Natl Acad Sci USA. 2010;107:20576-81. 
65. Kudo G, Suzuki S. Warming effects on growth, production, and vegetation structure of alpine shrubs: a five-year experiment in northern Japan. Oecologia . 2003;135:280-7.

66. Lenoir J, Gegout JC, Marquet PA, de Ruffray P, Brisse H. A significant upward shift in plant species optimum elevation during the 20th century. Science . 2008;320:1768-71.

67. Miller-Rushing AJ, Primack RB. Global warming and flowering times in Thoreau's concord: a community perspective. Ecology . 2008;89:332-41.

68. Yang T, Adams JM, Shi Y, He JS, Jing X, Chen LT, et al. Soil fungal diversity in natural grasslands of the Tibetan Plateau: associations with plant diversity and productivity. New Phytol. 2017;215:756-65.

69. Korkama T, Pakkanen A, Pennanen T. Ectomycorrhizal community structure varies among Norway spruce (Picea abies) clones. New Phytol. 2006;171:815-24.

70. Leski T, Aucina A, Skridaila A, Pietras M, Riepsas E, Rudawska M. Ectomycorrhizal community structure of different genotypes of Scots pine under forest nursery conditions. Mycorrhiza. 2010; 20:473-81.

71. Velmala SM, Rajala T, Haapanen M, Taylor AFS, Pennanen T. Genetic host-tree effects on the ectomycorrhizal community and root characteristics of Norway spruce. Mycorrhiza. 2013;23: 21-33.

72. Tani N, Tomaru N, Araki M, Ohba K. Genetic diversity and differentiation in populations of Japanese stone pine (Pinus pumila) in Japan. Can J Res. 1996;26:1454-62.

73. Takahashi K, Sato K. Summer ground temperature conditions in the Pinus pumila community in the alpine zone of the Daisetsuzan Mountains. Geogr Rev Jpn. 1996;69:693-705.

74. de Román M, de Miguel AM. Post-fire, seasonal and annual dynamics of the ectomycorrhizal community in a Quercus ilex L. forest over a 3-year period. Mycorrhiza . 2005;15:471-82.

75. Walker JF, Miller OK, Horton JL. Seasonal dynamics of ectomycorrhizal fungus assemblages on oak seedlings in the southeastern Appalachian Mountains. Mycorrhiza . 2008;18:123-32.

76. Gulser CE. I. A comparison of estimated and measured diurnal soil temperature through a clay soil depth. J Appl Sci. 2004;4: 418-23.

77. Nwankwo CO, An D. investigation of temperature variation at soil depths in parts of Southern Nigeria. Am. J Environ Eng. 2012;2: 142-7.

78. Takahashi K. Shoot growth chronology of alpine dwarf pine (Pinus pumila) in relation to shoot size and climatic conditions: a reassessment. Polar Biosci. 2006;19:123-32.

79. Kajimoto T. Photosynthesis and respiration of Pinus pumila needles in relation to needle age and season. Ecol Res. 1990;5: 333-40.

80. Baier R, Ingenhaag J, Blaschke H, Göttlein A, Agerer R. Vertical distribution of an ectomycorrhizal community in upper soil horizons of a young Norway spruce (Picea abies L. Karst.) stand of the Bavarian Limestone Alps. Mycorrhiza. 2006;16:197-206.

81. Courty PE, Franc A, Pierrat JC, Garbaye J. Temporal changes in the ectomycorrhizal community in two soil horizons of a temperate oak forest. Appl Environ Microbiol. 2008;74:5792-801.

82. Dickie IA, Xu B, Koide RT. Vertical niche differentiation of ectomycorrhizal hyphae in soil as shown by T-RFLP analysis. New Phytol. 2002;156:527-35.

83. Lindahl BD, Ihrmark K, Boberg J, Trumbore SE, Hogberg P, Stenlid J, et al. Spatial separation of litter decomposition and mycorrhizal nitrogen uptake in a boreal forest. New Phytol. 2007;173:611-20.

84. Rosling A, Landeweert R, Lindahl BD, Larsson KH, Kuyper TW, Taylor AFS, et al. Vertical distribution of ectomycorrhizal fungal taxa in a podzol soil profile. New Phytol. 2003;159:775-83.

85. Scattolin L, Montecchio L, Mosca E, Agerer R. Vertical distribution of the ectomycorrhizal community in the top soil of Norway spruce stands. Eur J Res. 2008;127:347-57.

86. Tedersoo L, Koljalg U, Hallenberg N, Larsson KH. Fine scale distribution of ectomycorrhizal fungi and roots across substrate layers including coarse woody debris in a mixed forest. New Phytol. 2003;159:153-65.

87. Buee M, Vairelles D, Garbaye J. Year-round monitoring of diversity and potential metabolic activity of the ectomycorrhizal community in a beech (Fagus silvatica) forest subjected to two thinning regimes. Mycorrhiza. 2005;15:235-45.

88. Kyaschenko J, Clemmensen KE, Hagenbo A, Karltun E, Lindahl BD. Shift in fungal communities and associated enzyme activities along an age gradient of managed Pinus sylvestris stands. ISME J. 2017;11:863-74.

89. Richard F, Roy M, Shahin O, Sthultz C, Duchemin M, Joffre R, et al. Ectomycorrhizal communities in a Mediterranean forest ecosystem dominated by Quercus ilex: seasonal dynamics and response to drought in the surface organic horizon. Ann Sci. 2011; 68:57-68.

90. Bödeker ITM, Clemmensen KE, de Boer W, Martin F, Olson A, Lindahl BD. Ectomycorrhizal Cortinarius species participate in enzymatic oxidation of humus in northern forest ecosystems. New Phytol. 2014;203:245-56.

91. Tedersoo L, Bahram M, Toots M, Diedhiou AG, Henkel TW, Kjoller R, et al. Towards global patterns in the diversity and community structure of ectomycorrhizal fungi. Mol Ecol. 2012; 21:4160-70.

92. Tedersoo L, Nara K. General latitudinal gradient of biodiversity is reversed in ectomycorrhizal fungi. New Phytol. 2010;185:351-4.

93. Randel WJ. The seasonal fingerprint of climate change. Science . 2018;361:227-8.

94. Santer BD, Po-Chedley S, Zelinka MD, Cvijanovic I, Bonfils C, Durack PJ, et al. Human influence on the seasonal cycle of tropospheric temperature. Science. 2018;361:245. 